\title{
Business discourse: Old debates, new horizons
}

\author{
FRANCESCA BARGIELA-CHIAPPINI AND CATHERINE NICKERSON
}

\begin{abstract}
The aim of this introductory article is twofold: (1) to locate business discourse in the context of some of the most salient debates within its cognate discipline, i.e., business communication, thus acknowledging epistemological and methodological indebtedness; and (2) to encourage the discussion around a distinct paradigm for business discourse as a new field of study by sketching out a first analytical framework that draws on multidisciplinary research and promotes multimethod research. The article argues that the first step towards a future multidisciplinary identity for business discourse depends on the operationalization of partnership research, i.e., collaborative research across associated disciplines.
\end{abstract}

\section{Old debates: A field in search of identity?}

In our earlier work, we defined business discourse as "talk and writing between individuals whose main work activities and interests are in the domain of business and who come together for the purpose of doing business" (BargielaChiappini and Nickerson 1999a: 2). We further pointed out that the interactants' status was the decisive element that distinguishes professional from business discourse, in that the former but not the latter, would involve a lay person. Moreover, business discourse refers to spoken and written communication that usually takes place within a corporate setting, whether physical (e.g., a manufacturing organization) or virtual (e.g., telework).

Within the remit (and word limit) of a position article, it is our intention to discuss the relevance of a business discourse approach to the analysis of communication in business settings. The significance of this move is best understood against the background of some of the ongoing debates within the broad field of business communication, such as the related issues of disciplinary definition and disciplinary boundaries and the discussions surrounding the plethora of methodological approaches that characterize the field. We will be arguing 
here for a discourse approach to business communication that seeks to reconcile discourse as product and discourse as action, represented in Figure 1 by two discrete discourse units of different orders of magnitude, i.e., generic discourses and typified actions, respectively sequences and nodes in the corporate communication web.

We both have a long-standing interest in the field, which stems from a combination of research and language teaching and training experience in corporate settings over a period of ten years. Field research in The Netherlands, Italy and Britain has brought us into direct contact with the textual and non-textual realizations of communication that constitute corporate life. Hence, we understand business discourse as a web of negotiated textualizations, constructed by social actors as they go about their daily activities in pursuit of organizational and personal goals. It is therefore language as social action that is the concern of business discourse research. Interestingly, the related field of sociolinguistics has already begun to explore the possible interface between research practice and social theory (Coupland 2001; see also Roberts 2001), a move similar to our proposed integration of social constructionism and structuration theory in the discourse-based interpretation of business writing (Bargiela-Chiappini and Nickerson 1999a). The revisiting of the relationship between organizational discourse and social theory (Westwood and Linstead 2001) is another powerful source of insight for business discourse research.

The discussion in Section 2 is articulated around two questions that dominated the literature on business communication in the Nineties: terminology and the variety of analytical and methodological approaches, the latter being a graphic illustration of the tension between the applied and the theoretical camps. The analytical framework that we present in Section 3 is our attempt to overcome damaging polarizations, while at the same time progressively incorporating insights from theoretical and empirical research under the more elastic and productive notion of business discourse. The last section of the article introduces four pieces of empirical research on business discourse that illustrate some of the richness of this growing field, intersecting the humanities and social sciences through its focus on language as work.

\section{Definitions, disciplinary boundaries and methods}

In our selective review of the field of business communication, which is heavily indebted to the United States for much of the current debate on disciplinary identity and formation, the issues of boundaries and status of the discipline as an academic subject emerge as salient and persistent concerns. In some quarters, the strong vocational orientation of business communication as a practical science is defended, but contrasted with management communication and English composition (Reinsch 1996: 35). In others, the controversy over bound- 
aries is resolved by granting business communication equal status alongside management, corporate and organizational communication, each of which is recognized as having a distinctive emphasis (Shelby 1996; Management Communication Quarterly Special Issue 1996). There is also a position that seems to accept that the criticisms raised against the field, i.e., a traditional concentration on the written mode, the proliferation of topics and the borrowings from many disciplines, may in fact be well-founded (Rivers 1994).

Disciplinary boundaries have not traditionally been an area of such concern on the European side of the Atlantic. However, the recent influx of researchers and practitioners based in Europe into the Association for Business Communication has resulted in several studies that have begun to address the concerns of business communication from a European perspective (Yli-Jokipii 1994; Charles 1996; Charles and Charles 1999; Louhiala-Salminen 1999; Verluyten 1997; Rogers 1998).

The European position on the purpose of business communication is perhaps encapsulated in the following statement by a Finnish scholar:

There seems to be a general understanding of the identification of the utilitarian goal of developing and disseminating knowledge that increases the effectiveness and efficiency of business operations (Louhiala-Salminen 1999: 26).

Arguably, the future of the discipline will be shaped by dialogue not only between the two traditional schools, the North American and the European, but also by the growing contribution of scholars from other countries (Rogers 1998).

The label of business communication seems to us best understood as an overarching category encompassing the whole field of communication studies in business settings, therefore, subsuming organizational and management communication, and discourse approaches (Murphy 1998; see also Rogers 2001 for a discussion of convergence within the field of business communication). ${ }^{1}$ This re-ordering of the relationships between related disciplines must not be seen as a rejection of the valuable individual contributions that each discipline can make to an improved understanding of the nature and role of communication in professional and corporate settings. Rather, it should be seen as an acknowledgement of the complex nature of corporate life, which is best approached from several complementary angles.

As the articles in the 1996 special issue of the Management Communication Quarterly clearly demonstrate, there is a wide scope for dialogue and possible cross-fertilization between disciplines, even if some of them (e.g., organizational communication), are seen to be more dependent on a "symbiotic relationship with the corporate world" (Mumby and Stohl 1996: 56). Finally, progressive disciplinary convergence may contribute to a re-definition of status and boundaries, which has preoccupied (mainly US) business communica- 
tion scholars, sometimes at the expense of contents, priorities and collaborative work (Shaw 1993; Reinsch 1996; Baker Graham and Thralls 1998; Verluyten 1997).

Together with discipline formation, the question of methods also remains open to lively debate. In their Guest Editorial for the 1998 special issue of the Journal of Business Communication on Discipline Formation, Baker Graham and Thralls (1998) lament the elusiveness of a common subject and method, after the failure of multidisciplinarity to provide a coherent identity. One solution could lie in a methodological shift. Given that quantitative methods appear to have been inadequate to meet the needs of business communication (Murphy 1998), the time has now come to opt for more qualitative approaches, such as, for example, the interpretative ethnography approach advocated by Smart (Smart 1998). This would enable the discipline to overcome an earlier criticism of being micro-analytical and skill-oriented, and it would open it up to new insights from the feeding disciplines such as rhetoric, sociology, psychology and linguistics, as well as to an appreciation of the influence of situational and contextual factors (Shaw 1993).

The variety of methodological approaches that have been employed in the analysis of written and spoken business discourse, e.g., conversation analysis, pragmatics, corpus linguistics, genre analysis and rhetorical analysis, social constructionism and impression management (Bargiela-Chiappini and Nickerson 1999b; Bargiela-Chiappini and Harris 1997b) is a stimulating start for a relatively new field. Epistemologically, the differences between approaches may be quite sharp, however, as is their engagement (or lack of it), with current theoretical debates. We believe that the multidisciplinary investigation of business discourse would best be served by a multimethod approach, already applied in fields as diverse as cross-cultural management (e.g., Jackson 1995) and public discourse analysis (Scollon et al. 1999). Following the recent call for a "multidisciplinary, multimethod, and multifaceted" discipline (Rogers 2001: 18), business discourse must progress towards partnership research, a shared agenda between researchers working within associated disciplines (BargielaChiappini and Nickerson 2001).

Business discourse, ideally adopting partnership research as a methodological approach, is our response to some of the controversial issues surrounding business communication research. This approach offers the opportunity to work towards a certain degree of methodological and theoretical consolidation or convergence, without which interdisciplinarity will remain elusive. The choice of the disciplinary label of business discourse rather than business communication is significant and deliberately programmatic. It suggests that progressive disciplinary consolidation can only be achieved through a commitment to epistemological and methodological sharing between discourse-based disciplines, which will be the first step towards defining a common purpose 
around which collaborative research can flourish. The relevance of context to the interpretation of discourse in fields such as organizational communication (Jablin and Putman 2001), critical discourse analysis (Wodak and Meyer 2001), organizational ethnography (Weber 2001) and sociolinguistics (Coupland, Sarangi, and Candlin 2001) makes them all potential partners in this enterprise.

Business discourse as contextual and intertextual, self-reflexive and selfcritical, although not necessarily political, is founded on the twin notions of discourse as situated action and of language as work. This perspective seems now quite remote from early discussions on the nature of professional language that originated from within LSP, or Language for Specific Purposes (Johns 1986). In its attempt to recontextualize discourse within the current dialogues between related disciplines and combined approaches, and between praxis and social theory, business discourse also remains distinct from recent developments in LSP (Swales 1999) and ESP (Louhiala-Salminen 2002).

\section{New horizons: Towards an integrated framework for the analysis of business discourse}

In the epilogue to a special issue of TEXT on professional-client discourse, Sarangi (1998) reflects on the variety of analytical frameworks in use not only as one of the characteristics of the professional discourse field, but also as a feature of earlier collections on both professional discourse (Gunnarsson, Linell, and Bordberg 1997) and business discourse (Bargiela-Chiappini and Harris 1997b). In The Languages of Business (Bargiela-Chiappini and Harris 1997b), for example, the understanding of the crucial role and the multidimensionality of culture (as exemplified in all types of business interaction in the collection) was a development of findings from earlier comparative research in multinational corporations (Bargiela-Chiappini and Harris 1997c, especially chapters 6 and 8). The final product of this development was a first analytical framework for the analysis of business discourse consisting of five dimensions: national culture, corporate culture, interactions, generic types of discourse and individual language systems (Bargiela-Chiappini and Harris 1997a: 14). Arguably, the explanatory power of such models relies on the quality and quantity of sound empirical research. Both should grow diachronically as increased access to relevant data and the continued refinement of theoretical insight, deepen our understanding of business discourse.

The model of business discourse that we are about to discuss (Figure 1), incorporates insights from genre and discourse analysis, intercultural communication and organizational theory, into a context-sensitive analytical framework for the study of discourse in corporate settings. A framework that encompasses micro, meso and macro dimensions lends itself, at least ideally, to multilevel, 
multimethod research programmes involving multidisciplinary teams. ${ }^{2}$ However, as we suggest in the previous section, given the well-known constraints and restrictions under which researchers too often operate, a more modest, medium-term objective must be to achieve increased communication between researchers across disciplinary boundaries. ${ }^{3}$

Similar multidimensional approaches have also been central to the work of other researchers. For example, Nickerson (2000: 39) views the social context for a multinational corporation as a series of four hierarchical levels, consisting of the multinational corporation as a discrete social entity at one level (following Blyler and Thralls 1993), followed by a set of (typified) situations that occur and re-occur as the corporation pursues its institutional goals. At the next level, within each situation, the corporation evolves a series of typified communication practices, or genres, in order to accomplish the necessary (communicative) action, and finally, these genres are realized as individual textualizations (Miller 1980, 1984; Yates and Orlikowski 1992).

The need for multidimensional analysis reflects the complexity of organizational contexts, where factors such as corporation size and activity, organizational structure, (communication) technology, national and corporate cultures (Driskill 1989), not to mention methods of control and tasks (Suchan and Dulek 1998), all affect discourse practices. The organic relationship between context and genre is an on-going concern of organizational communication research, be it the correlation between business and genre type (Van Nus 1999), or between national culture and foreign language choice (Vandermeeren 1999).

Figure 1 combines elements of our two earlier models (Bargiela-Chiappini and Harris 1997a: 14; Nickerson 2000: 39) into a more complex multidimensional framework that aims to account for (some of) the contextual influences and their generic discourse realizations. The framework is ordered into three hierarchical analytical levels:

1. A macro level, which includes factors such as national and regional cultures, ${ }^{4}$ which are partly responsible for the formation of generic discourses;

2. A meso level, which includes factors such as organizational culture(s), business type, methods of control in place, and which also partly shape generic discourses;

3. A micro level, or interactional level, where individual socio-psychological profiles and interactional preferences are most prominent and are identifiable in the pragma-linguistic features of "typified actions" (Miller 1980, 1984) or textualizations.

In Figure 1, the macro-meso discourse realisation called generic discourses refers to the discourse types that characterize corporate settings and that are realized through a network of micro discourse formations, or textualizations, i.e., the instantiations of typified actions (Miller 1980, 1984). Discourse realizations at all levels depend on the language systems, a notion that indicates 


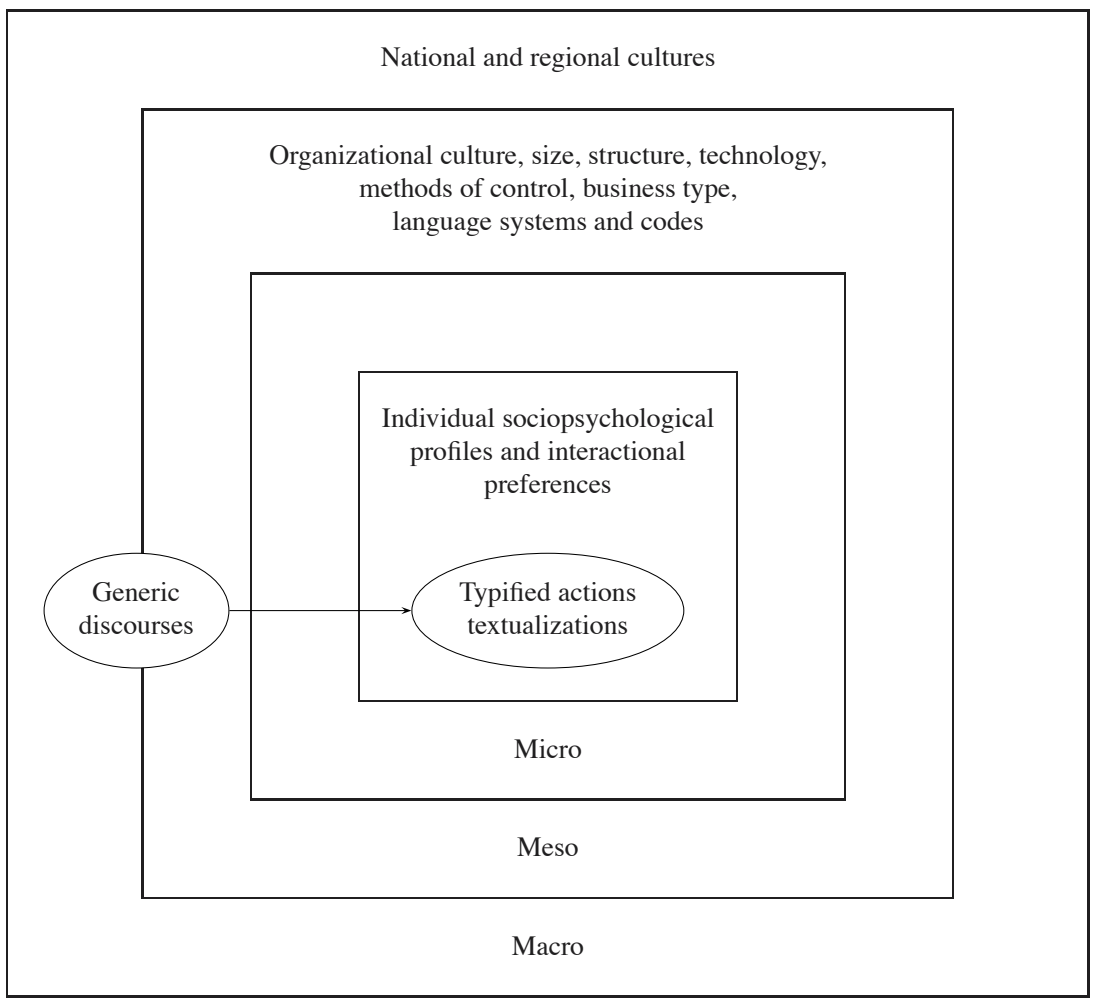

Figure 1. A framework for the analysis of business discourse

the coexistence of two or more languages (particularly in multinational and multiethnic businesses), typically English used alongside the local national or regional language (Nickerson 2000; Brownell 1999). In addition to these language systems, codes are a salient feature of larger organizations, where a multidivisional structure and the degree of specialization promote the evolution and maintenance of technical jargons and group-lects. Language systems and codes clearly affect the interactions that take place at the micro level, or the typified actions (e.g., meetings, job interviews, report writing etc.), discursively embodied in textualizations, the object of study for business discourse analysts.

The approach to business discourse which informs the analytical framework in Figure 1 aims to be: (1) integrated in its multilevel ordering of expandable interplaying factors, and (2) integrative in its projected outcomes, which 
include dialogue between research and teaching/training needs, and between theoretical advances and practical applications (Bargiela-Chiappini 2001). The inclusion of meso and macro levels of analysis forces field researchers to be aware that business discourse is embedded in a wider context than the immediate one surrounding the specific interaction that they are investigating (Lovitt 1999; Gunnarsson 2000). It also demands sensitivity to the disciplinary and theoretical debates surrounding relevant areas such as corporate culture, multilingual communication, organizational power and control etc. It is almost impossible to expect that the individual organizational ethnographer will be familiar with a multidisciplinary, multimethod reality such as the one represented in Figure 1, hence the necessity to forge links across disciplines, as well as continuing to work closely with the business community for increased perspective (see Bhatia 1993).

On a final note, while language, or rather, discourse, must remain our privileged locus of interpretation, we believe that the significance of writing (and speaking) in business transcends local practices and reflects a reality beyond the confines of individuals' text or interactions:

The social nature of language at work is exemplified in business writing practices, both as processes and as products. Writing in business contexts is often, generically speaking, hybrid, in that many texts display signs of intertextuality and interdiscursivity; collective, in that texts are often the products of a multiple authorship process; structure-dependent and structure-shaping, in that writing always takes place in a cultural and historic context by which it is influenced and which, in turn, it influences (Bargiela-Chiappini and Nickerson 1999a: 18, original emphasis).

\section{In this issue}

In this introductory article we have focussed on issues of identity and method that business discourse may be seen to share with associated fields of enquiry, such as business communication. We have also sketched out what we think is an innovative and pragmatic way of tackling some of the problems of multidisciplinary research. Partnership research may seem a long way away for some of us, but beginning to face the complex issues that it inevitably raises is a sound first step towards engagement with the much broader movement for integration that is a concern for the social sciences and the humanities. ${ }^{5}$

All of the articles in this issue show (varying degrees of) sensitivity to the need for contextualisation in business discourse analysis. Acknowledging the pervasiveness, complexity and ambiguity of the notion of context connects us to current debates on what actually constitutes context in the first place. Our framework is a first attempt at capturing the multilayered nature of this notion, 
without, however, claiming to be comprehensive or even easily applicable to data collection and analysis in business settings. The difficulties of fieldwork and interpretation will continue to challenge the linguist-turned-ethnographer, not least because the framework only obliquely reveals certain epistemological assumptions about the nature of organizational life.

The ordering of the papers that follows is inspired by their increasing degree of engagement with and problematization of issues of contextualization and multidisciplinarity. Hence, Grahame Bilbow's analysis of commissive speech acts in intercultural (Hong Kong Chinese and Western) business meetings illustrates the potential of a well-established micro-analytical approach. Moreover, the sequencing and realization preferences that the author attributes to culture point to the interplay between micro and macro levels. Individual cognitive profiles belong to the former, of which language fluency may be considered a component. As Bilbow remarks, the non-native command of English puts the Chinese interactants at a disadvantage with respect to their Western counterparts. The practical implications of the findings of this research are quite clear. Not showing commitment as expected in Western style meetings may attract a label of non-team players for the non-native speakers of English, in this case Hong Kong Chinese, with all the consequences that this mis-construal has for interpersonal perceptions and for business relationships.

Culture looms large in Didar Akar's article on Turkish business discourse. The author alerts us to the distinctiveness of the Turkish case, with its historical roots in two continents and two very different rhetorical traditions. Modernity, and the increasingly dominant role of the private sector economy in a country traditionally dominated by the state, adds a complicating twist to an already intricate pattern of influences that the author uncovers in her study of a large archive of internal and external correspondence from four companies. The link between macro factors and micro practices is illustrated with examples from memoranda and facsimiles, two text types which are conventionalized in form and content and are therefore comparable, and which are also texts used by employees at all levels. Akar's three-tiered analysis looks at text typology, rhetorical choices and discourse functions through a multidisciplinary lens. Beside national and cultural factors, the author also highlights two other meso-factors affecting her corporate texts, i.e., company size and communication technology.

Local and global cultures and media preferences also feature in Julio Gimenez's study of electronic mediated communication between an American corporation and its Argentinian subsidiary. Here, the macro dimension of culture is expanded to accommodate the phenomenon of (economic) globalization. Although the firm's own culture may be portrayed by its American headquarters as "global", the article shows how resistance to cultural assimilation in local subsidiaries leads to internal tensions. Argentinian managers seek to main- 
tain their distinctiveness in their preference for facsimiles, or even face-to-face communication, rather than electronic mail. Gimenez's findings support previous research on corporate relational difficulties between headquarters and subsidiaries (e.g. Nickerson 2000). His analysis of communicative practices, (code selection, transmission patterns and translation conventions), illuminated by semi-structured interviews with the administrative assistants who also selected the (non-confidential) documents for the author, reveal a subsidiary company divided between headquarters-imposed practices and local preferences. The final choice of the optimal response in given circumstances rests with the Argentinian managers who are therefore left to take on and to resolve the conflict between the distant global culture and their local work practices.

Back in Europe, Gina Poncini explores the ways in which language, especially English as a lingua franca, shapes the business relationship in and beyond business meetings. In a first study of this kind, the author observes and audio-records the meetings of an Italian company's international distributors, usually attended by about 25 individuals representing up to 15 different countries in Europe, Asia and North America. Instead of concentrating on instances of miscommunication, for which such meetings are fertile ground, Poncini chooses to look at the enabling role that language, in this case English, plays in multicultural business encounters. To this effect, she employs the notion of business relationships, to capture the complexity of relations at play in multicultural business meetings, where individuals bring distinctive sets of business relationships to the table. Cultural differences may not be sufficient, or even necessary, to explain the potential for cooperation and conflict embedded in these relational webs.

Poncini's article illustrates a multicategory analytical approach that highlights ways in which the language of the meetings constructs and enables multicultural business activities, roles and relationships. For each category, she also discusses its discursive role. So, for example, through pronominal choice, the interactants construct flexibility, ambiguity and complexity, as well as reciprocity and cooperation. Positive evaluation is used strategically to create a shared image of the company, while the effects of negative evaluation are contained by hedges or by selectively addressing small groups of participants in the meeting. Interactional strategies such as frame and footing shifts are also salient in the meetings and in association with the linguistic choices already mentioned, they map the dynamics of changing participant roles.

In avoiding the temptation to explain away interactional patterns in multicultural business encounters exclusively in terms of cultural differences, Ponchini's study complements and consolidates the insights of the preceding three. By acknowledging culture as one of the contributing factors, it nevertheless privileges language, or rather discourse, as the vehicle through which difference at all levels, including cultural difference, is mediated, contested, ne- 
gotiated, internalized and acted upon, in a multiparty, multicultural business interaction.

\author{
Nijmegen University \\ $<$ c.nickerson@let.kun.nl>
}

\author{
Nottingham Trent University
}

<francesca.bargiela@ntu.ac.uk>

\title{
Notes
}

1. For the purposes of this discussion, we are treating "corporate communication" as synonymous with "organizational communication".

2. Recent work by Ruth Wodak at the European Commission provides an excellent example of the effectiveness of working with a multidisciplinary team when funding allows (Wodak and van Dijk 2000).

3. Despite often insurmountable practical obstacles, there is increasing support for working from "various disciplinary perspectives" with a "multidisciplinary community of researchers" (Goswami 1999). Zachry (2000), for example, uses the case of rhetorical genre analysis to illustrate the multidisciplinary possibilities afforded by a shared research approach.

4. In their discussion on international document design, Tebeaux and Driskill (1999) point out that corporate and national cultures must be viewed not as separate entities, but as interacting within a single context.

5. The pioneering action of a journal of the calibre of Human Relations, which has enthusiastically adopted an integration manifesto, should alert us to importance of this evolution and to its direct relevance to business discourse research.

\section{References}

Baker Graham, Margaret and Charlotte Thralls (1998). Connections and fissures: Discipline formation in business communication. Journal of Business Communication 35 (1): 7-13.

Bargiela-Chiappini, Francesca (2001). Partnership research and teaching. Paper presented at the international conference on Prospettive linguistiche della Nuova Europa all'alba del terzo millennio, 9-10 Novembre, Universita’ L. Bocconi, Milan.

Bargiela-Chiappini, Francesca and Sandra J. Harris (1997a). The languages of business: Introduction and overview. In The Languages of Business: An International Perspective, Francesca Bargiela-Chiappini and Sandra J. Harris (eds.), 1-20. Edinburgh: Edinburgh University Press.

Bargiela-Chiappini, Francesca and Sandra J. Harris (eds.) (1997b). The Languages of Business: An International Perspective. Edinburgh: Edinburgh University Press.

Bargiela-Chiappini, Francesca and Sandra J. Harris (1997c). Managing Language: The Discourse of Corporate Meetings. Amsterdam and Philadelphia: John Benjamins.

Bargiela-Chiappini, Francesca and Catherine Nickerson (1999a). Business writing as social action. In Writing Business: Genres, Media and Discourses, Francesca Bargiela-Chiappini and Catherine Nickerson (eds.), 1-32. London and New York: Longman.

- (1999b). Writing Business: Genres, Media and Discourses. London and New York: Longman.

- (2001). Partnership research: A response to Priscilla Rogers. Journal of Business Communication 38 (3): 248-251.

Bhatia, Vijay K. (1993). Analysing Genre: Language Use in Professional Settings. London: Longman.

Blyler, Nancy R. and Charlotte Thralls (eds.). (1993). Professional Communication: The Social Perspective. Newbury Park, London, New Dehli: Sage Publications. 
Brownell, Judi (1999). Effective communication in multicultural organizations: A receiver-defined activity. In Exploring the Rhetoric of International Professional Communication: An Agenda for Teachers and Researchers, Carl R. Lovitt with Dixie Goswami (eds.), 171-190. Amityville, NY: Baywood.

Charles, Mirjaliisa (1996). Business negotiations: Interdependence between discourse and the business relationship. English for Specific Purposes 15 (1): 19-36.

Charles, Mirjaliisa and David Charles (1999). Sales negotiations: Bargaining through tactical summaries. In Business English: Research into Practice, Martin Hewings and Catherine Nickerson (eds.), 72-83. London and New York: Longman.

Coupland, Nikolas (2001). Introduction: Sociolinguistic theory and social theory. In Sociolinguistics and Social Theory, Nikolas Coupland, Srikant Sarangi, and Christopher N. Candlin (eds.), 1-26. London: Pearson Education Ltd.

Coupland, Nikolas, Srikant Sarangi, and Christopher N. Candlin (eds.). (2001). Sociolinguistics and Social Theory. London: Pearson Education Ltd.

Driskill, Linda P. (1989). Understanding the writing context in organisations. In Writing in the Business Professions, Myra Kogen (ed.), 125-145. Urbana, Illinois: National Council of Teachers of English/The Association for Business Communication.

Goswami, Dixie (1999). Afterword: Teaching and research directions for international professional communication. In Exploring the Rhetoric of International Professional Communication: An Agenda for Teachers and Researchers, Carl R. Lovitt with Dixie Goswami (eds.), 305-310. Amityville, NY: Baywood.

Gunnarsson, Britt-Louise (2000). Discourse, organizations and national cultures. Discourse Studies 2 (1): 5-33.

Gunnarsson, Britt-Louise, Per Linell, and Bengt Bordberg (eds.) (1997). The Construction of Professional Discourse. London and New York: Longman.

Jablin, Frederic M. and Linda L. Putman (eds.) (2001). The Handbook of Organizational Communication. Thousand Oaks, CA: Sage.

Jackson, Terence (1995). Cross-cultural Management. Oxford: Butterworth-Heinemann Ltd.

Johns, Ann M. (1986). The language of business. Annual Review of Applied Linguistics (Language and the Professions) 7: 3-17.

Louhiala-Salminen, Leena (1999). From business correspondence to message exchange: The notion of genre in business communication. Ph.D. diss., Jyväskylä: Centre for Applied Language Studies, University of Jyväskylä.

- (2002). The fly's perspective: Discourse in the daily routine of a business manager. English for Specific Purposes 21: 211-231.

Lovitt, Carl R. (1999). Rethinking the role of culture in international professional communication. In Exploring the Rhetoric of International Professional Communication: An Agenda for Teachers and Researchers, Carl R. Lovitt with Dixie Goswami (eds.), 1-16. Amityville, NY: Baywood.

Management Communication Quarterly Special Issue (1996). Special Issue: Management, Business, Organizational, and Corporate Communication: A Discussion of our Disciplines. 10 (1): 3-130.

Miller, Carolyn R. (1980). Rules, context, and technical communication. Journal of Technical Writing and Communication 10 (2): 149-158.

- (1984). Genre as social action. Quarterly Journal of Speech 70: 151-167.

Mumby, Dennis K., and Cynthia Stohl (1996). Disciplining organizational communication studies. Management Communication Quarterly 10 (1): 50-72.

Murphy, Mary Ann (1998). Re-viewing business communication: A response to Carmichel, White-Mills and Rogers, and Krapels and Arnold. Journal of Business Communication 35 (1): $128-137$ 
Nickerson, Catherine (2000). Playing the Corporate Language Game. An Investigation of the Genres and Discourse Strategies in English used by Dutch Writers Working in Multinational Corporations. (vol. 15). Amsterdam-Atlanta: Rodopi.

Reinsch, N. Lamar jr. (1996). Business communication: Present, past and future. Management Communication Quarterly, 10 (1): 27-49.

Rivers, William E. (1994). Studies in the history of business and technical writing: A bibliographic essay. Journal of Business and Technical Communication, Special Issue: Social and Historical Perspectives on Business and Technical Communication 8 (1): 6-57.

Roberts, Celia (2001). 'Critical' social theory: Good to think with or something more? In Sociolinguistics and Social Theory, Nikolas Coupland, Srikant Sarangi and Christopher N. Candlin (eds.), 323-333. London: Pearson Education Ltd.

Rogers, Priscilla (1998). National agendas and the English divide. Business Communication Quarterly 61 (3): 79-129

- (2001). Convergence and commonality challenge business communication research (Outstanding Researcher Lecture). The Journal of Business Communication 38 (1): 14-23.

Sarangi, Srikant (1998). Rethinking contextualization in professional discourse: An epilogue. TEXT 18 (2): 301-318.

Scollon, Ron, Vijay Bhatia, David Li, and Vicky Yung (1999). Blurred genres and fuzzy identities in Hong Kong public discourse: Foundational ethnographic issues in the study of reading. Applied Linguistics 20 (1): 22-43.

Shaw, Gary (1993). The shape of the field: Communication as a hybrid discipline. Journal of Business Communication 30 (3): 297-313.

Shelby, Annette (1996). A discipline orientation: Analysis and critique. Management Communication Quarterly 10 (1): 98-105.

Smart, Graham (1998). Mapping conceptual worlds: Using interpretive ethnography to explore knowledge-making in a professional community. Journal of Business Communication 35 (1): $111-127$.

Suchan, Jim, and Ron Dulek (1998). From text to context: An open systems approach to research in written business communication. The Journal of Business Communication 35 (1): 87-110.

Swales, John M. (1999). Languages for specific purposes. Annual Review of Applied Linguistics 20: $59-76$.

Tebeaux, Elizabeth and Linda P. Driskill (1999). Culture and the shape of rhetoric: Protocols of international document design. In Exploring the Rhetoric of International Professional Communication: An Agenda for Teachers and Researchers, Carl R. Lovitt with Dixie Goswami (eds.), 211-252. Amityville, NY: Baywood.

Vandermeeren, Sonja (1999). English as a lingua franca in corporate writing. In Writing Business: Genres, Media and Discourses, Francesca Bargiela-Chiappini and Catherine Nickerson (eds.), 273-291. London and New York: Longman.

Van Nus, Miriam (1999). Can we count on your bookings of potatoes to Madeira? Corporate context and discourse practices in direct sales letters. In Writing Business: Genres, Media and Discourses, Francesca Bargiela-Chiappini and Catherine Nickerson (eds.), 181-206. London and New York: Longman.

Verluyten, S. Paul (1997). Business communication and intercultural communication in Europe: The state of the art. Business Communication Quarterly 60 (2): 135-143.

Weber, Florence (2001). Settings, interactions and things: A plea for multi-integrative ethnography. Ethnography 2 (4): 475-500.

Westwood, Robert and Stephen Linstead (eds.) (2001). The Language of Organization. London: Sage.

Wodak, Ruth and Teun van Dijk (eds.) (2000). Racism at the Top. Parliamentary Discourses on Ethnic Issues in Six European States. Klagenfurt: Drava.

Wodak, Ruth and Michael Meyer (2001). Methods of Critical Discourse Analysis. London: Sage. 


\section{Francesca Bargiela-Chiappini and Catherine Nickerson}

Yates, JoAnne, and Wanda Orlikowski (1992). Genres of organizational communication: A structurational approach to studying communication and media. Academy of Management Review 17 (2): 299-326.

Yli-Jokipii, Hilkka (1994). Requests in Professional Discourse: A Cross-Cultural Study of British, American and Finnish Business Writing. (Annales Academiae Scientiarum Fennicae Dissertationes Humanarum Litterarum 71.) Helsinki: Suomalainen tiedeakatemia.

Zachry, Mark (2000). Conceptualizing communicative practices in organizations: Genre-based research in professional communication. Business Communication Quarterly 63 (4): 95-101. 